\title{
Analisis political uncertainty dan non-performing loan pada bank non devisa di Indonesia
}

\author{
${ }^{1 *}$ Ali Jufri, ${ }^{2}$ Rista Puput Aryanti, ${ }^{3}$ Desy Ayu Krisna Murti, ${ }^{4}$ Bhenu Artha \\ ${ }^{1}$ Universitas Muhammadiyah Cirebon, Jl. Tuparev No. 70 Cirebon \\ 2,3,4 Universitas Widya Mataram, Dalem Mangkubumen KT III/237 Yogyakarta 55132 \\ *e-mail korespondensi: jufri.ali2014@gmail.com
}

\begin{tabular}{l|l}
\hline \hline \multicolumn{1}{c}{ Keywords } & \multicolumn{1}{c}{ Abstract } \\
\hline \hline $\begin{array}{l}\text { political } \\
\text { uncertainty, non- } \\
\text { performing loan, } \\
\text { bank, non-foreign } \\
\text { exchange banks, } \\
\text { general election }\end{array}$ & $\begin{array}{l}\text { Political risk stems from potential government actions, other political forces, and } \\
\text { differences in national cultures within and across countries, which imply uncertainty } \\
\text { future economic arrangements and political risks in the context of the banking sector } \\
\text { affect bank risk. Through growing government uncertainty and information } \\
\text { asymmetry. This study aims to determine the differences in non-performing loans } \\
\text { (NPL) at non-foreign exchange banks in Indonesia for the two-year period before } \\
\text { and after the general election. This research is a quantitative study, which uses non- } \\
\text { foreign exchange banks as the research object. The sample in this study were non- } \\
\text { foreign exchange banks in Indonesia that issued financial reports for the years 2010 } \\
\text { - 2016 and obtained 13 banks as samples. The data analysis using the SPSS } \\
\text { application is a t-test because this study examines the difference in non-performing } \\
\text { loans (NPL) before and after the general election. The results of this study indicate } \\
\text { that there is no difference in NPL before and after the 2014 general election in non- } \\
\text { foreign exchange banks in Indonesia. }\end{array}$ \\
&
\end{tabular}

\begin{tabular}{|c|c|}
\hline Kata Kunci & Abstrak \\
\hline $\begin{array}{l}\text { ketidakpastian } \\
\text { politik, kredit } \\
\text { macet, bank, bank } \\
\text { non-devisa, } \\
\text { pemilihan umum }\end{array}$ & $\begin{array}{l}\text { Risiko politik berasal dari tindakan potensial pemerintah, kekuatan politik lainnya, } \\
\text { dan perbedaan budaya nasional di dalam dan lintas negara, yang menyiratkan } \\
\text { ketidakpastian tentang kemungkinan perubahan dalam kebijakan pemerintah dan } \\
\text { pengaruh kebijakan tersebut pada pengaturan ekonomi masa depan dan risiko politik } \\
\text { dalam konteks sektor perbankan mempengaruhi risiko bank melalui ketidakpastian } \\
\text { pemerintah dan asimetri informasi yang semakin besar. Penelitian ini bertujuan } \\
\text { untuk mengetahui perbedaan non-performing loan (NPL) pada bank non devisa di } \\
\text { Indonesia periode dua tahun sebelum dan sesudah pemilihan umum. Penelitian ini } \\
\text { merupakan penelitian kuantitatif, yang menggunakan bank non devisa sebagai objek } \\
\text { penelitian. Sampel dalam penelitian ini adalah bank non devisa di Indonesia yang } \\
\text { menerbitkan laporan keuangan tahun } 2010 \text { - } 2016 \text { dan diperoleh } 13 \text { bank sebagai } \\
\text { sampel. Analisis data yang menggunakan aplikasi SPSS adalah uji beda atau t-test } \\
\text { karena penelitian ini menguji perbedaan non-performing loan (NPL) sebelum dan } \\
\text { sesudah pemilihan umum. Hasil penelitian ini menunjukkan bahwa tidak ada } \\
\text { perbedaan NPL sebelum dan sesudah pemilihan umum tahun } 2014 \text { pada bank non } \\
\text { devisa di Indonesia. }\end{array}$ \\
\hline
\end{tabular}




\section{PENDAHULUAN}

Risiko politik berasal dari tindakan potensial pemerintah, kekuatan politik lainnya, dan perbedaan budaya nasional di dalam dan lintas negara (Ashraf, 2017; Huang et al., 2015). Hal tersebut menyiratkan ketidakpastian tentang kemungkinan perubahan dalam kebijakan pemerintah dan pengaruh kebijakan tersebut pada pengaturan ekonomi masa depan dan risiko politik dalam konteks sektor perbankan mempengaruhi risiko bank melalui ketidakpastian pemerintah dan asimetri informasi yang semakin besar (Al-Shboul et al., 2020). Risiko politik mempengaruhi pengambilan risiko bank melalui kualitas lembaga hukum dan persaingan industri perbankan (Ashraf, 2017). Risiko politik mempengaruhi efisiensi dan stabilitas bank (Miah \& Uddin, 2017). Beberapa literatur telah mempertimbangkan hubungan antara risiko politik dan bank dengan berfokus pada faktor penentu pengambilan risiko bank (Ashraf, 2017; Cubillas \& González, 2014; Haque \& Brown, 2017; Herrala \& Turk-Ariss, 2016). Pemilihan umum yang dilaksanakan tahun 2014 merupakan agenda terbesar pada tahun tersebut. Pemilihan umum merupakan agenda terbesar tahun 2014 (Setiawanto, 2014). Pemilihan umum memungkinkan situasi perekonomian berubah yang dapat menyebabkan perubahan pada non performing loan (NPL), dimana data menunjukkan pada bulan Juli 2014 NPL sektor kontruksi sebesar 4,43 persen, perdagangan 3,06 persen, jasa sosial 2,96 persen, dan pertambangan 3,09 persen (Setiawan, 2014).

Bank menghadapi banyak risiko karena struktur dinamis dan kompleksitas lingkungan ekonomi tempat beroperasinya (Ekinci \& Poyraz, 2019). Risiko yang dihadapi bank dapat dikategorikan menjadi enam yaitu risiko kredit, risiko likuiditas, risiko pasar, risiko operasional, risiko nominal, dan risiko hukum (Wernz, 2014). Kredit merupakan aktivitas yang menghasilkan pendapatan utama bagi bank, akan tetapi proses ini mengandung risiko yang besar baik bagi pemberi pinjaman maupun peminjam dan tingginya kredit bermasalah pada neraca bank mengurangi profitabilitasnya dan mempengaruhi kinerja bank (Ekinci \& Poyraz, 2019). Manajemen risiko kredit yang efektif menjadi penting di Lembaga keuangan untuk kelangsungan dan pertumbuhannya (Afriyie \& Akotey, 2011). Manajemen risiko kredit yang efektif akan mendukung keberlanjutan dan profitabilitas bank dan berkontribusi pada stabilitas ekonomi serta alokasi modal yang efisien dalam perekonomian (Psillaki et al., 2010). Risiko yang timbul dari kegagalan mitra dagang untuk memenuhi kewajiban kontraktualnya tepat waktu atau di lain waktu dapat membahayakan kelangsungan bisnis bank, dan di sisi lain bank dengan risiko kredit tinggi memiliki risiko kebangkrutan tinggi yang membahayakan deposan (Ekinci \& Poyraz, 2019). Risiko kredit dapat diproksikan dalam non-performing loan (NPL) pada laporan keuangan bank. NPL merupakan rasio perbandingan antara pembiayaan bermasalah terhadap total pembiayaan yang diberikan (Yundi \& Sudarsono, 2018). Penelitian ini bertujuan untuk mengetahui perbedaan nonperforming loan (NPL) pada bank non devisa di Indonesia periode dua tahun sebelum dan sesudah pemilihan umum. 


\section{KAJIAN TEORI DAN HIPOTESIS}

Ketidakstabilan politik yang melekat dalam proses ini menghadirkan suatu skenario ketidakpastian yang memengaruhi keputusan perusahaan, meskipun biasanya proses pemakzulan memprovokasi lingkungan ketidakstabilan politik, dalam kasus Brasil, wakil presiden, anggota partai memenuhi harapan akan perubahan positif (Jucá \& Fishlow, 2020). Pemakzulan itu (Jucá \& Fishlow, 2020) mewakili hilangnya kepercayaan pada kelas politik, tetapi juga perubahan haluan yang diantisipasi dari ekonomi negara, sehingga akibatnya, perusahaan tidak mengurangi investasinya.

Bank-bank dengan tingkat pinjaman yang tinggi terlihat mengganggu kualitas asetnya karena tidak dapat menagih pinjaman, dan terlihat bahwa mereka diarahkan untuk masuk ke dalam pemikiran negatif bank terhadap sektor riil dan ketinggian suku bunga juga berdampak negatif pada kecukupan modal bank Turki dan profitabilitas mereka (Yurttadur, et al., 2019). NPL berperan penting dalam mempengaruhi penilaian peringkat negara di atas dan di atas pengaruh ketidakpastian, pertumbuhan PDB, rasio utang pemerintah terhadap $\mathrm{PDB}$, rasio investasi terhadap $\mathrm{PDB}$, dan rasio keseimbangan fiskal terhadap PDB (Boumparis et al., 2019). Pada saat yang sama, keputusan pemeringkatan negara sendiri mempengaruhi NPL, dan penurunan peringkat sovereign secara intuitif memicu penurunan peringkat bank yang pada gilirannya menyebabkan penurunan pasokan pinjaman dan, pada saat yang sama, menambah beban pembiayaan kembali pinjaman yang ada, sehingga memicu peningkatan NPL (Boumparis et al., 2019).

Hipotesis dalam penelitian ini adalah sebagai berikut:

Ho : Tidak ada perbedaan NPL sebelum dan sesudah pemilihan umum tahun 2014 pada bank non devisa di Indonesia.

Ha : Ada perbedaan NPL sebelum dan sesudah pemilihan umum tahun 2014 pada bank non devisa di Indonesia.

\section{METODE PENELITIAN}

Penelitian ini merupakan penelitian kuantitatif (Bajpai, 2018), yang menggunakan bank non devisa sebagai objek penelitian. Sampel dalam penelitian ini adalah bank non devisa di Indonesia yang menerbitkan laporan keuangan tahun 2010 - 2016, yang ditetapkan dengan metode purposive sampling (Bajpai, 2018), dan diperoleh 13 bank sebagai sampel. Analisis data yang digunakan menggunakan aplikasi SPSS 25 adalah uji beda atau t-test karena penelitian ini menguji perbedaan non-performing loan (NPL) sebelum dan sesudah pemilihan umum. Variabel yang digunakan dalam penelitian ini adalah Non-Performing Loan (NPL), yang diproksikan dengan data NPL pada laporan keuangan (Elekdag et al., 2020). 


\section{HASIL DAN PEMBAHASAN}

Penggunaan uji beda memerlukan uji normalitas, untuk mengetahui distribusi data dalam penelitian ini. Data dalam penelitian ini diuji menggunakan Kolmogorov-Smirnov (Erlangga \& Mawardi, 2017). Hasil uji normalitas dapat dilihat pada tabel berikut ini:

Tabel 1

Hasil uji normalitas

\begin{tabular}{|c|c|c|c|c|}
\hline \multicolumn{5}{|c|}{ One-Sample Kolmogorov-Smirnov Test } \\
\hline & & & sebelum & sesudah \\
\hline $\mathrm{N}$ & & & 26 & 26 \\
\hline \multirow{2}{*}{ Normal Parameters ${ }^{\mathrm{a}, \mathrm{b}}$} & Mean & & 3.7943 & 4.2207 \\
\hline & Std. Deviation & & 1.25590 & 1.65468 \\
\hline \multirow[t]{3}{*}{ Most Extreme Differences } & Absolute & & .130 & .170 \\
\hline & Positive & & .088 & .143 \\
\hline & Negative & & -.130 & -.170 \\
\hline Test Statistic & & & .130 & .170 \\
\hline Asymp. Sig. (2-tailed) $)^{\mathrm{c}}$ & & & $.200^{\mathrm{d}}$ & .050 \\
\hline \multirow[t]{3}{*}{ Monte Carlo Sig. (2-tailed) ${ }^{\mathrm{e}}$} & Sig. & & .298 & .050 \\
\hline & $99 \%$ Confidence Interval & Lower Bound & .286 & .044 \\
\hline & & Upper Bound & .310 & .056 \\
\hline
\end{tabular}

a. Test distribution is Normal.

b. Calculated from data.

c. Lilliefors Significance Correction.

d. This is a lower bound of the true significance.

e. Lilliefors' method based on 10000 Monte Carlo samples with starting seed 221623949.

Hasil uji normalitas menunjukkan angka signifikansi data sebelum sebesar 0.298 dan data sesudah sebesar 0.050, maka dapat disimpulkan bahwa data berdistribusi normal. Hasil uji t dapat dilihat pada tabel 2 berikut ini:

Tabel 2

Hasil Uji t

\begin{tabular}{|c|c|c|c|c|c|c|c|c|c|}
\hline \multicolumn{10}{|c|}{ Paired Samples Test } \\
\hline \multicolumn{10}{|c|}{ Paired Differences } \\
\hline & & \multirow[t]{2}{*}{ Mean } & \multirow[t]{2}{*}{$\begin{array}{c}\text { Std. } \\
\text { Deviation }\end{array}$} & \multirow[t]{2}{*}{$\begin{array}{l}\text { Std. } \\
\text { Error } \\
\text { Mean }\end{array}$} & \multicolumn{2}{|c|}{$\begin{array}{l}95 \% \text { Confidence } \\
\text { Interval of the } \\
\text { Difference }\end{array}$} & \multirow[t]{2}{*}{$\mathrm{t}$} & \multirow[t]{2}{*}{ df } & \multirow[t]{2}{*}{$\begin{array}{l}\text { Sig. } \\
(2- \\
\text { tailed) }\end{array}$} \\
\hline & & & & & Lower & Upper & & & \\
\hline $\begin{array}{c}\text { Pair } \\
1\end{array}$ & $\begin{array}{l}\text { sblm - } \\
\text { ssdh }\end{array}$ & $\begin{array}{c}- \\
4264 \\
2\end{array}$ & 1.92836 & $\begin{array}{c}.3781 \\
8\end{array}$ & $\begin{array}{c}- \\
1.2053 \\
0\end{array}$ & $\begin{array}{c}.3524 \\
6\end{array}$ & $\begin{array}{c}- \\
1.12 \\
8\end{array}$ & 25 & .270 \\
\hline
\end{tabular}

Tabel tersebut menunjukkan bahwa nilai sig $=0.270$, lebih besar dari 0.05 yang berarti bahwa tidak ada perbedaan NPL sebelum dan sesudah pemilihan umum. Ketidakpastian politik menyebabkan perusahaan tidak mengurangi investasinya (Jucá \& Fishlow, 2020), hasil senada dengan penelitian ini. Pinjaman yang mengalami kenaikan akan menyebabkan NPL cenderung stabil karena di sisi lain terdapat kenaikan pinjaman yang bermasalah. Perusahaan menggunakan lebih banyak hutang bank selama pemilihan umum (Ben-Nasr et 
$a l ., 2020)$. Hal tersebut dapat menyebabkan NPL mengalami kecenderungan tidak berubah karena adanya keseimbangan antara kenaikan jumlah kredit dengan debitur yang mengalami masalah pembayaran pinjaman. Hasil berbeda dalam penelitian lain yaitu terdapat pengaruh positif political uncertainty terhadap risiko kredit tingkat perusahaan di 30 negara, dimana hal tersebut dipengaruhi oleh tingkat perusahaan dan negara (Liu \& Zhong, 2017). Hasil berbeda ini disebabkan adanya perbedaan jumlah sampel penelitian, baik periode waktu, jumlah perusahaan, maupun jumlah negara yang diteliti, sehingga menyebabkan hasil yang berbeda.

\section{KESIMPULAN DAN SARAN}

Hasil penelitian ini menunjukkan bahwa tidak ada perbedaan NPL sebelum dan sesudah pemilihan umum tahun 2014 pada bank non devisa di Indonesia, dimana penelitian ini dilaksanakan pada periode dua tahun sebelum dan sesudah pemilu. Saran untuk penelitian selanjutnya adalah menambah variabel yang diteliti antara lain Tobin's Q, CAR, dan ROE.

\section{DAFTAR PUSTAKA}

Afriyie, H. O., \& Akotey, J. O. (2011). Credit Risk Management and Profitability of selected rural banks in Ghana. Journal of Banking and Finance, 1(1), 1-18.

Al-Shboul, M., Maghyereh, A., Hassan, A., \& Molyneux, P. (2020). Political risk and bank stability in the Middle East and North Africa region. Pacific-Basin Finance Journal, 60, 101291.

Ashraf, B. N. (2017). Political institutions and bank risk-taking behavior. Journal of Financial Stability, 29, 13-35.

Bajpai, N. (2018). Business Research Methods. Pearson Education India.

Ben-Nasr, H., Bouslimi, L., Ebrahim, M. S., \& Zhong, R. (2020). Political uncertainty and the choice of debt sources. Journal of International Financial Markets, Institutions and Money, 64, 101142.

Boumparis, P., Milas, C., \& Panagiotidis, T. (2019). Non-performing loans and sovereign credit ratings. International Review of Financial Analysis, 64, 301-314.

Cubillas, E., \& González, F. (2014). Financial liberalization and bank risk-taking: International evidence. Journal of Financial Stability, 11(1), 32-48.

Ekinci, R., \& Poyraz, G. (2019). The Effect of Credit Risk on Financial Performance of Deposit Banks in Turkey. Procedia Computer Science, 158, 979-987.

Elekdag, S., Malik, S., \& Mitra, S. (2020). Breaking the Bank? A Probabilistic Assessment of Euro Area Bank Profitability. Journal of Banking and Finance, 120, 105949.

Erlangga, O. P., \& Mawardi, I. (2017). Pengaruh Total Aktiva, Capital Adequacy Ratio (CAR), Finance To Deposit Ratio (FDR) Dan Non Performing Financing (NPF) Terhadap Return On Assets (ROA) Bank Umum Syariah Di Indonesia Periode 20102014. Jurnal Ekonomi Syariah Teori Dan Terapan, 3(7), 561.

Haque, F., \& Brown, K. (2017). Bank ownership, regulation and efficiency: Perspectives from the Middle East and North Africa (MENA) Region. International Review of Economics and Finance, 47, 273-293. 
Herrala, R., \& Turk-Ariss, R. (2016). Capital accumulation in a politically unstable region. Journal of International Money and Finance, 64, 1-15.

Huang, T., Wu, F., Yu, J., \& Zhang, B. (2015). International political risk and government bond pricing. Journal of Banking and Finance, 55, 393-405.

Jucá, M. N., \& Fishlow, A. (2021). Political uncertainty of impeachment upon corporate investment decisions. Borsa Istanbul Review, 21(2), 149-160.

Liu, J., \& Zhong, R. (2017). Political uncertainty and a firm's credit risk: Evidence from the international CDS market. Journal of Financial Stability, 30, 53-66.

Miah, M. D., \& Uddin, H. (2017). Efficiency and stability: A comparative study between islamic and conventional banks in GCC countries. Future Business Journal, 3(2), 172185.

Psillaki, M., Tsolas, I. E., \& Margaritis, D. (2010). Evaluation of credit risk based on firm performance. European Journal of Operational Research, 201(3), 873-881.

Setiawan, Sakina Rakhma Diah (2014). NPL Perbankan Membaik di Semester II. Tersedia di:https://nasional.kompas.com/read/2014/09/15/191213326/NPL.Perbankan.Membai k.di.Semester.II, diakses pada April 2021.

Setiawanto, Budi. (2014). Tahapan Pemilu 2014. Tersedia di: https://www.antaranews.com/berita/424177/tahapan-pemilu-2014, diakses pada April 2021.

Wernz, J. (2014). Bank Management and Control: Strategy Pricing, Capital, and Risk Management (Second Edition). Springer International Publishing;Springer.

Yundi, N. F., \& Sudarsono, H. (2018). Pengaruh Kinerja Keuangan terhadap Return on Asset (ROA) Bank Syariah di Indonesia. Al-Amwal : Jurnal Ekonomi Dan Perbankan Syari'ah, 10(1), 18.

Yurttadur, M., Celiktas, E., Celiktas, E. (2019). Place Non-performing the Turkish Banking Sector World of Conference Place of Loans in the Turkish Banking Sector The Place Non-performing Loans in the Turkish Banking Banking Sector World of Place of Loans in the Turkish Sector The Place of Non-performing. Procedia Computer Science, 158, 766-771. 